\title{
Physicochemical Processes Controlling the Source-Term from Tank Residuals
}

(Project Number: 81893)

\section{Principal Investigator}

Dr. B. P. McGrail

Pacific Northwest National Laboratory

P.O. Box 999, MSIN K6-81

Richland, WA 99352

509-376-9193 (phone)

509-376-2210 (fax)

pete.mcgrail@pnl.gov

\section{Contributors and Collaborators}

B. K. McNamara

Pacific Northwest National Laboratory

P.O. Box 999, MSIN P7-25

Richland, WA 99352

509-376-1408 (phone)

509-373-9675 (fax)

Bruce.Mcnamara@pnl.gov

G. J. Lumetta

Pacific Northwest National Laboratory

P.O. Box 999, MSIN P7-22

Richland, WA 99352

509-376-6911 (phone)

509-373-9675 (fax)

gregg.lumetta@pnl.gov
S. V. Mattigod

Pacific Northwest National Laboratory

P.O. Box 999, MSIN K6-81

Richland, WA 99352

509-376-4311 (phone)

509-376-5368 (fax)

shas.mattigod@pnl.gov

S. L. Wallen

Department of Chemistry

University of North Carolina at

Chapel Hill

Campus Box 3290

Chapel Hill, NC 27599-6011

919-962-2933 (phone)

wallen@email.unc.edu 


\section{Research Objective}

After remediation and closure of the high-level waste tanks at Hanford (and at other DOE sites), residual radionuclide-bearing solids will remain in the form of sludge and hard heel adhering to the inner surfaces of the tanks. Radionuclide release from these residuals represents a potentially significant source of contaminants migrating in the sediments underlying the tanks. A recent composite analysis for the Hanford Site has shown the radionuclide source term from the residual solids to be one of the most significant long-term dose contributors on site, essentially equivalent in magnitude to a number of well-known discharges from leaking single-shell tanks. However, this assessment was based on a highly conservative release model for the tank residuals. The conservative model is being used in lieu of a true scientific understanding of the processes controlling the release rate from the sludge that is applicable to the Hanford vadose zone environment. Currently, the U.S. Department of Energy (DOE) is planning to spend hundreds of millions of dollars to remove $99 \%$ or more of the waste from Hanford high-level waste tanks that may have no real long-term environmental benefit. Through this project, we will significantly improve the fundamental scientific basis for estimating the release rate of ${ }^{99} \mathrm{Tc}$, the principal long-term dose contributor from tank residual wastes.

We envision an improved conceptual model that considers diffusion of water and oxygen in the sludge under conditions of partial hydraulic saturation, but $100 \%$ relative humidity, consistent with the subsurface environment at Hanford. Key chemical processes are also considered, including the oxidation of reduced Tc compounds in the sludge and the chemical changes in sludge phase assemblage that will occur over time. A combination of novel experimental methods is proposed to investigate these processes. This comprehensive study will provide a sound technical basis for DOE and local stakeholders to make more informed cost/benefit/risk decisions regarding closure of Hanford high-level waste tanks.

\section{Research Progress and Implications}

This project was initiated in FY02 and is being performed cooperatively between Pacific Northwest National Laboratory (PNNL) and the University of North Carolina at Chapel Hill (UNC-CH). Efforts to date have focused on producing and characterizing tank sludge simulants that will be the focus of studies over the next 2 years. Unexpected difficulties were encountered in retaining $\mathrm{Re}$, a non-radioactive surrogate for ${ }^{99} \mathrm{Tc}$, during sludge preparation. Incorporation of a reducing agent during the sludge preparation solved this problem.

During preparation of SAPO-34 zeolite to be used in Re adsorption studies, we unexpectedly synthesized a pure sodalite with perrhenate in the beta cage. This compound has never been reported in the literature. Consequently, additional characterization work is underway to define the structure and bonding in this compound. 


\section{Preparation of a Re-Bearing Sludge}

A literature study was carried out to investigate tank sludge types that might retain ${ }^{99} \mathrm{Tc}$. Specifically, the waste type was to be contained in Hanford single shell tanks (SSTs) and originate from the plutonium-uranium extraction (PUREX), oxidation-reduction (redox), or $\mathrm{BiPO}_{4}$ processes. Additionally, this sludge should exhibit sustained levels of ${ }^{99} \mathrm{Tc}$ after waste retrieval operations. Existing analytical data associated with sludge washing and sludge leaching studies, carried out at PNNL and at Los Alamos National Laboratory, indicated that sludge in tank series B-201-204 and T-101-111 should retain ${ }^{99} \mathrm{Tc}$ after sluicing and retrieval operations. Specifically, the data suggested that B-202 and T-111 will retain $98 \%$ and $88 \%{ }^{99} \mathrm{Tc}$, respectively, in the remaining sludge solids after waste retrieval operations.

A T-111 sludge simulant was chosen, and preparations began with caustic precipitation of metal nitrate salts and $\left(\mathrm{NH}_{4}\right)_{2} \mathrm{ReCl}_{6}$ as a technetium mimic. The supernatant was decanted from centrifuged sludge, and the sludge washed in 0.1- $\underline{\mathrm{M}}$ hydroxide. This type of preparation apparently promoted oxidation of the precipitated $\mathrm{ReO}_{2}$, and it readily washed from the sludge. A number of alternative preparations were tried with similar results. An alternative, successful small-scale preparation utilized metal chloride salts with thiosulfate as reductant. Reagents were purged under argon, and preparations were carried out in a glove bag under argon. The final sludge product contained $1.28 \mathrm{mg} \mathrm{ReO} / \mathrm{g}$ wet sludge as analyzed by inductively coupled plasma mass spectroscopy . Scale-up of this procedure was hampered by various solubility issues and also limited by the time required to prepare multigram quantities of pure $\left(\mathrm{NH}_{4}\right)_{2} \mathrm{ReCl}_{6}$. The yield of Re was only about $10 \%$ from this preparation, and the loss may be due to the relatively high solubility of $\mathrm{ReO}_{2}$ as the hydrous oxide in basic solution. The final wet sludge product, however, has the appearance of the actual, as-received T-111 sludge. It has very high water content and contains about $1.28 \mathrm{mg} \mathrm{ReO} / \mathrm{g}$ wet sludge. Approximately 750 grams of the wet sludge have been prepared.

\section{Readsorption on Zeolites}

The objective of this task is to synthesize selected zeolite minerals that are present in tank sludge and conduct adsorption experiments to ascertain their ability to retard transport of ${ }^{99} \mathrm{Tc}$. We developed a synthesis scheme to obtain samples of pure nitrated cancrinite. Additionally, we have synthesized pure samples of SAPO-34 using morpholine templates. 
During these studies, we unexpectedly synthesized samples of pure sodalite with perrhenate substitution in the beta cage, as shown in Figure 1. This compound has never been reported in literature. The significance of this discovery is that perrhenate (and, by analogy, pertechnetate) can also be trapped in the sodalite structure.

Preliminary characterization of this material has been completed and a manuscript is in preparation for publication. Figure 2 shows $\mathrm{x}-$ ray powder diffraction data for the sodalite. As shown, the Rietveld refinement of the structure agrees well with the experimental x-ray diffraction (XRD) pattern, indicating that perrhenate ion is entrapped in the beta cage of sodalite.

A Raman spectrum was also collected on the $\mathrm{Na}_{8}\left(\mathrm{AlSiO}_{4}\right)_{6}\left(\mathrm{ReO}_{4}\right)_{2}$ powder. The Raman scattered light was collected at room temperature in $180^{\circ}$ mode with a fiber optic probe. Scattered laser light is passed through a holographic notch filter with an optical density of 4 but $80 \%$ transmissivity for Raman scattered light. The probe is coupled to a Holospec (Kaiser Optical Systems) spectrograph. The spectrograph features fast f/1.8 optics, HoloPlex ${ }^{\mathrm{TM}}$ transmission grating, and back-illuminated chargecoupled device detector. Incident light was provided by a 532-nm diode-pumped ND:YAG laser operated at about $150 \mathrm{~mW}$. Exact assignment of the peaks

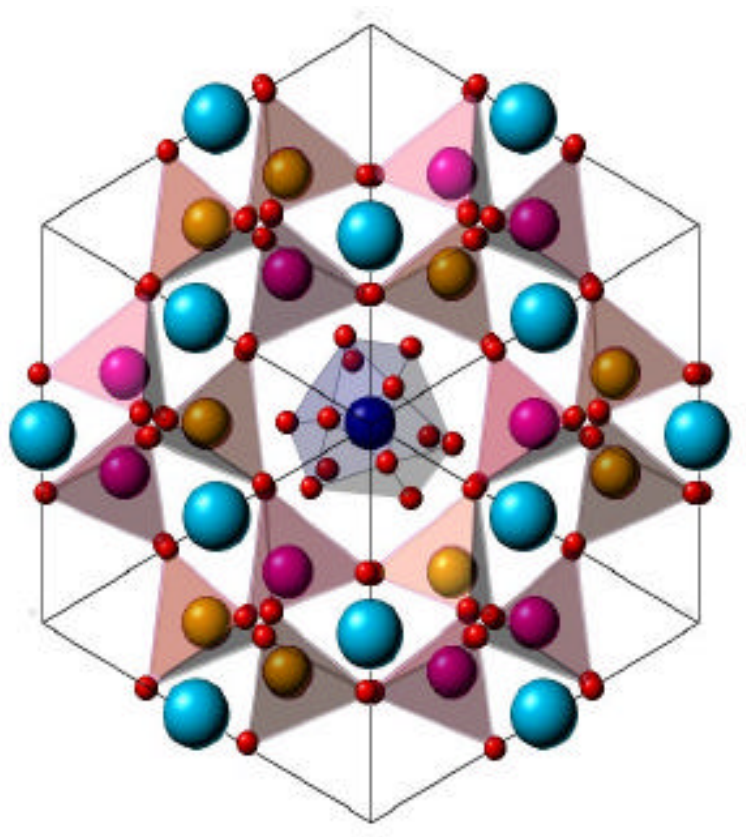

Figure 1. Crystal Structure of Sodalite (Re), $\mathrm{Na}_{8}\left(\mathrm{AlSiO}_{4}\right)_{6}\left(\mathrm{ReO}_{4}\right)_{2}$ Viewed Along (111)

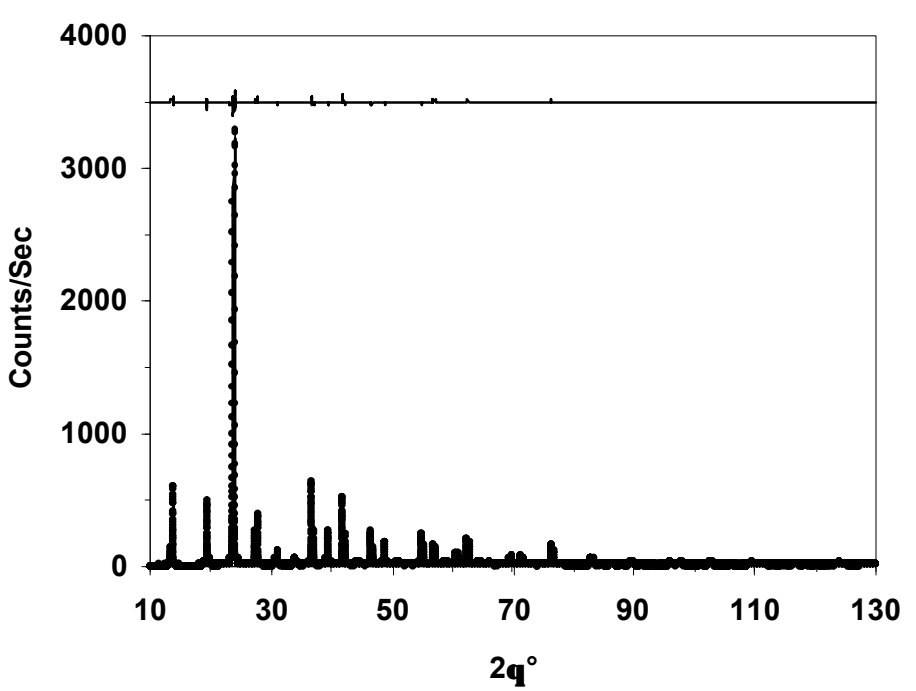

Figure 2. Experimental Versus Refined XRPD Data for Sodalite (Re), $\mathrm{Na}_{8}\left(\mathrm{AlSiO}_{4}\right)_{6}\left(\mathrm{ReO}_{4}\right)_{2}$ 
in Figure 3 is still in progress. However, the peak at $975 \mathrm{~cm}^{-1}$ is probably an asymmetric T-O-T stretching vibration ( $\mathrm{T}$ being the atom at the center of a tetrahedron, e.g., Si or Al) $[1,2]$. The peak at $923 \mathrm{~cm}^{-1}$ may be a $v_{3}$ stretching vibration for $\mathrm{ReO}_{4}$ - in tetrahedral coordination [3].

\section{Diffusion in Tank Sludge}

The goal of the UNC-CH group in the initial phase of this project is to incorporate luminescent and para-

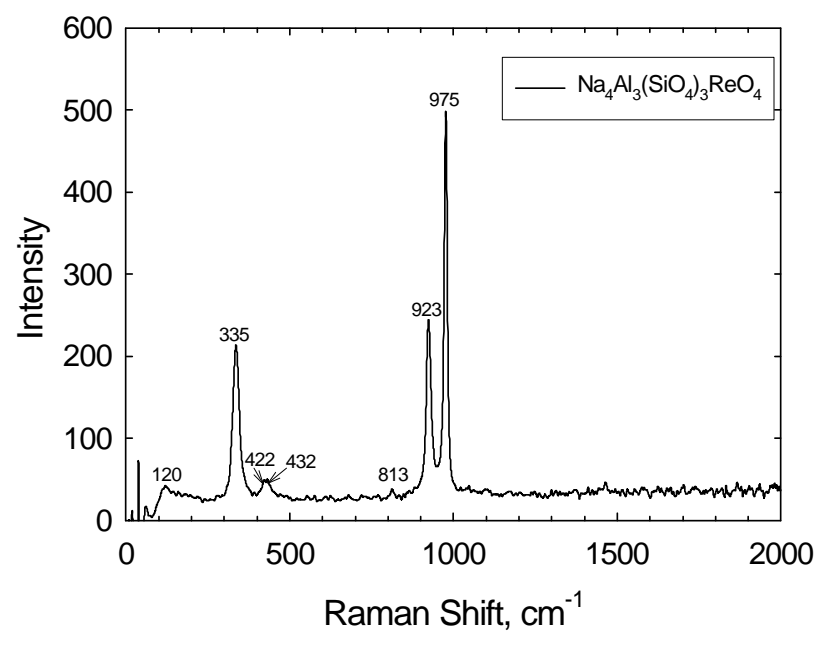

Figure 3. Raman Spectrum of $\mathrm{Na}_{8}\left(\mathrm{AlSiO}_{4}\right)_{6}\left(\mathrm{ReO}_{4}\right)_{2}$ magnetic species into a silica nanoparticle for the development of nuclear magnetic resonance and luminescence measurements of $\mathrm{H}_{2} \mathrm{O}$ and $\mathrm{O}_{2}$ diffusion coefficients in single-phase sludgesimulant samples. The synthetic procedure is based on a reverse microemulsion process that involves performing a solgel reaction in the interior $\mathrm{H}_{2} \mathrm{O}$ pool of the microemulsion system. An example of the type of particles typical in this process are shown in Figure 4. The control of the particle morphology and the effect of various solvents on this system are currently being investigated. The Triton-N101 surfactant used previously in cyclohexane has been determined to have limitations with respect to the size and polydispersion of the nanoparticle reporters. The incorporation of the luminescent $\mathrm{Eu}^{3+}$ is being pursued through the processing of $\mathrm{Eu}\left(\mathrm{NO}_{3}\right)_{3}$ in basic solution to produce a hydrated precipitate that was peptized with acid to produce a sol that was incorporated into the reverse microemulsion solgel silica synthesis. Preliminary results indicate incorporation of the luminescent system into the silica particles; however, the particle size and polydispersity have not been evaluated.

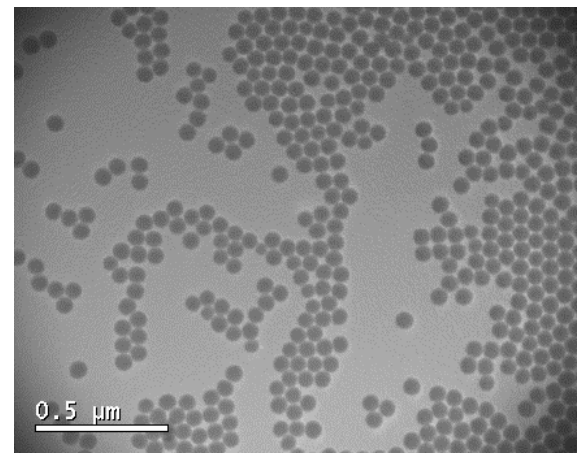

Figure 4. Silica Nanoparticles Produced via Microemulsion Technique

\section{Planned Activities}

We have successfully prepared a T-111 tank sludge simulant with sufficient Re to support planned measurements of its transport and oxidation behavior. These experiments will begin sometime in early FY03. A manuscript on the newly discovered perrhenate sodalite is in preparation. Future work on pure zeolite phases will focus on the degree of substitutions in 
cancrinite and sodalite structures in mixed oxyanion systems $\left(\mathrm{NO}_{3} / \mathrm{ReO}_{4}\right)$. Experiments to understand potential adsorption and desorption mechanisms of $\mathrm{TcO}_{4}$ on cancrinite, sodalite, and SAPO-34 materials will also begin.

\section{References Cited}

Ariai J and SRP Smith. 1981. The Raman Spectrum and Analysis of Phonon Modes in Sodalite. J. Phys. C: Solid State Phys. 14:1193-1202.

de Man AJM and RA van Santen. 1992. The Relation Between Zeolite Framework Structure and Vibrational Spectra. Zeolites 12:269-279.

Brenchley ME and MT Weller. 1994. Synthesis and Structures of $\mathrm{M}_{8}\left[\mathrm{AlSiO}_{4}\right]_{6} \cdot\left(\mathrm{XO}_{4}\right)_{2}, \mathrm{M}=$ Na, Li, K; X = Cl, Mn Sodalites. Zeolites 14:1994. 